\title{
Interpenetrating networks of carboxymethyl tamarind gum and chitosan for sustained delivery of aceclofenac
}

\author{
Kailas Krishnat MALI, Shashikant C DHAWALE, Remeth J DIAS, Vijay D HAVALDAR, Pankaj R KAVITAKE
}

\begin{abstract}
The aim of present investigation was to characterize carboxymethyl tamarind gum (CMTG) based interpenetrating networks (IPNs) of aceclofenac for site specific sustained delivery. The drug loaded IPNs were prepared by using chitosan and CMTG as polymers and gluteraldehyde as crosslinking agent. The IPNs were characterized by Attenuated total reflectanceFourier transform infrared (ATR-FTIR) spectroscopy, thermal analysis, $\mathrm{X}$-ray powder diffraction and solid state ${ }^{13} \mathrm{C}$-nuclear magnetic resonance spectroscopy. The prepared IPNs were evaluated for the drug entrapment efficiency and equilibrium swelling. The drug release from IPNs was studied in $0.1 \mathrm{NHCl}$ for $2 \mathrm{~h}$ followed by phosphate buffer $\mathrm{pH} 6.8$ for further $10 \mathrm{~h}$ and compared with commercial tablet. The results of ATR-FTIR
\end{abstract}

and thermal analysis for blank IPNs indicated intercalation of polymeric chains of crosslinked CMTG and chitosan. The results of solid state characterization revealed that the aceclofenac is compatible with IPNs. Entrapment efficiency of IPNs was found to be increased with increase in crosslinker concentration as well as amount of CMTG. The equilibrium swelling study indicated $\mathrm{pH}$ dependent swelling of IPNs. The drug release by IPNs showed sustained release of aceclofenac upto $12 \mathrm{~h}$ while commercial formulation showed fast release within $8 \mathrm{~h}$. From the results, it can be concluded that the IPNs of CMTG and chitosan has potential in development of site specific sustained drug delivery.

Key words: Interpenetrating networks; carboxymethyl tamarind gum; chitosan; aceclofenac; crosslinking.
Kailas Krishnat Mali, Pankaj R Kavitake

Department of Pharmaceutics, YSPM's Yashoda Technical Campus, Faculty of

Pharmacy, Wadhephata, Satara, 415011 Maharashtra, India

Remeth J Dias

Department of Pharmacy, Government Polytechnic, National Highway No 6, Jalgaon-425 002, India

Vijay D Havaldar

Department of Pharmacy, Adarsh Institute of Pharmacy, Vita, Sangli-415 311, India

Shashikant C Dhawale

Department of Pharmacology, School of Pharmacy, SRTM University, Nanded, 431 606, Maharashtra, India

Corresponding Author:

Kailas Krishnat Mali

e-mail:malikailas@gmail.com

Submitted / Gönderilme: 04.05.2017 Revised / Düzeltme: 20.06.2017 Accepted / Kabul: 28.06.2017

How to cite this article: Mali KK, Dhawale SC, Dias RJ, Havaldar VD, Kavitake PR. Interpenetrating networks of carboxymethyl tamarind gum and chitosan for sustained delivery of aceclofenac. Marmara Pharm J 2017; 21 (4): 771-782

\section{Introduction}

Amongst various routes of administration, oral route of drug delivery is widely used for sustained drug delivery because of advantages like ease of administration, improved patient compliance, site specific delivery and reduction in dosing frequency [1]. The multiple dosing is required in case of chronic disorders and may be associated with certain side effects. In order to reduce dosing frequency and associated side effects, sustained and site specific drug delivery approach has been widely applied [2]. The goal of site specific drug delivery system is to maintain a dose of drug at desired target site for specified time. The site specific drug delivery directly targets the dose of drug to certain biological location. It may be preferable in certain situations like drug instability, low solubility, shorter half life, poor absorption, low specificity and low therapeutic index [3]. 
It has been shown that single polymer is unable to give oral site specific sustained drug release and hence combination of polymers could be better option. One of the promising approach for oral site specific sustained drug delivery is interpenetrating networks (IPNs)[4]. IPNs are polymeric network of two or more polymers that forms a rigid composite network structure by cross-linking of at least one polymer in presence of other. The combination of polymers ensures improved mechanical strength, loading capacity, sustained and controlled drug release[5,6]. IPNs provides space for drug encapsulation in three dimensional structure which may or may not be cross linked [7]. IPNs are prepared to combine individual properties of polymers, suggesting that combination or mixture of polymers can be effectively used for drug delivery system. The natural and synthetic polymers can be widely used to prepare IPNs [8]. Natural polymers combined with other natural, semisynthetic or synthetic polymers can achieve combined polymer properties for better management of drug delivery.

Chitosan is a natural, $\mathrm{pH}$ sensitive biopolymer obtained from deacetylation of chitin. It is biocompatible, biodegradable polysaccharide, which is degraded by human enzymes [9]. Chitosan is widely utilized in various drug delivery systems, tissue engineering and also in food technology [10]. It is not stable in acidic environment due to its fast dissolution leading to fast release of drug in stomach [11]. Hence, alone chitosan is not suitable for development of site specific sustained drug delivery. The combination of chitosan with other polymer may prove effective in such cases. Chitosan, having a amino group shows net positive charge which may be combined or cross-linked with negatively charged $\mathrm{COO}^{-}$ to form rigid composite structure of IPNs.

Tamarind gum (TG) is another natural polymer which can be used in formation of IPNs $[8,12]$. It is cheap and biocompatible polysaccharide used as emulsifier, suspending, gelling and binding agent [6,13]. TG has some disadvantages like unpleasant odor, dull color and fast degradation [14]. To overcome these problems carboxymethylation of TG is done [15]. Carboxymethyl tamarind gum (CMTG) is a semisynthetic derivative of TG which imparts viscosity, enhances shelf life, shows anionic character and controls swelling as well as drug release properties $[7,14]$. Thus, it may be good release retardant material in drug delivery [16-20]. The CMTG based formulations have been reported in literature for bone tissue engineering which supports adhesion and production of osteoblast precursor cells [21,22]. It has also been used to proliferate human keratinocyte cells in skin tissue engineering application [23]. Also, it has potential biomedical application suggesting minimal cytotoxicity towards mammalian cells with affinity towards bacterial cell wall [24]. Novel CMTG-g-polyacrylonitrile hydrogel has also been reported as an adsorbant in literature for the diaper application [25]. The interpenetrating hydrogels of CMTG and alginate for delivery of acyclovir has been reported in literature [18].

CMTG has low cost than other semi-synthetic derivatives of polysaccharides. It may be the suitable alternative from biomaterial point of view because the structure involves the backbone as that of cellulose which is hydrophilic in nature. The IPNs of chitosan with tamarind gum was reported in literature for delivery of aceclofenac [6]. However, no study has been reported till date, where combination of semi synthetic polymer CMTG and chitosan has been used for preparation of IPNs. Therefore it was proposed to prepare IPNs using CMTG with chitosan so that site specific extended release of aceclofenac can be warranted.

In this study aceclofenac was used as model drug. It is a non-steroidal anti-inflammatory drug (NSAID) with short half-life (4h) used for the symptomatic treatment of pain and inflammation. Due to short half-life of aceclofenac, it is required to administer frequently [26]. Hence, aceclofenac is an ideal candidate for developing a sustained release site specific dosage form.

Considering above facts, an attempt was made to develop $\mathrm{pH}$ dependent site specific IPNs of aceclofenac using CMTG and chitosan. The prepared IPNs were characterized by ATR-FTIR, thermal analysis, X-ray diffraction and solid state ${ }^{13} \mathrm{C}$ NMR. Also, IPNs were evaluated for equilibrium swelling and drug release.

\section{Results and Discussion}

\subsection{Preparation of IPNs}

For the preparation of IPNs at least two polymers are required, from which one polymer should be crosslinked by crosslinker. In present study, chitosan was used as base polymer and was crosslinked using gluteraldehyde to form network while the second polymer, CMTG, gets entangled in crosslinked chains of chitosan. Further, it was proposed that secondary $-\mathrm{OH}$ of CMTG may get crosslinked with gluteraldehyde. Also, the intercalation of second polymer in chitosan may be feasible due to formation of polyelectrolyte complex between free $-\mathrm{NH}_{3}{ }^{+}$of chitosan and $-\mathrm{COO}^{-}$of CMTG. The proposed structure of IPNs is given in Figure 1. 


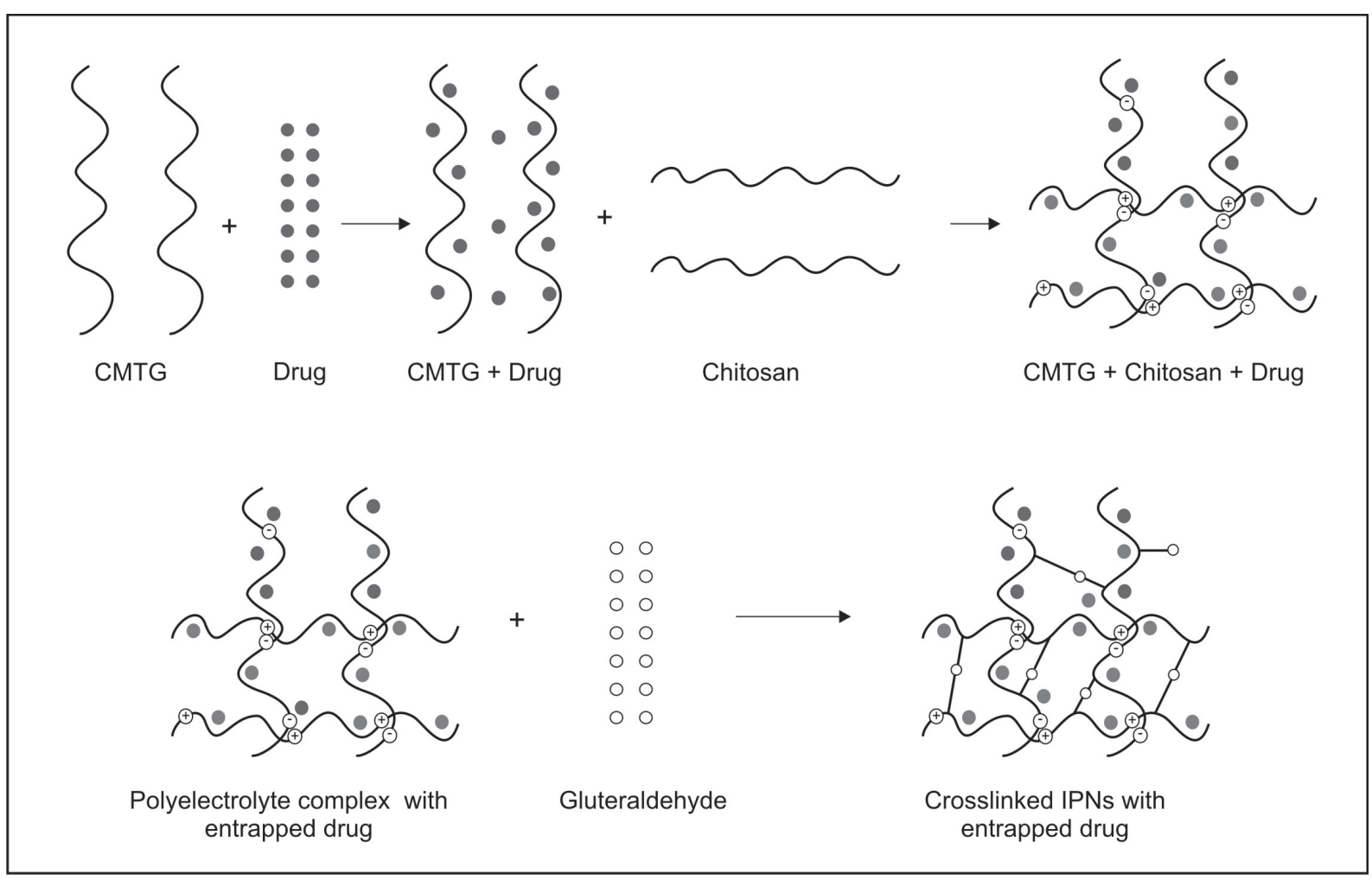

Figure 1. Proposed structure of IPN entrapped with drug

\subsection{Drug entrapment efficiency}

Drug entrapment within polymeric complex was expressed as percentage ratio of actual aceclofenac entrapped in polymeric complex with that of initial amount of aceclofenac used in formulation. Drug entrapment efficiency of IPNs was observed in the range of 61.3 to $88.5 \%$ (see Table 1). In case of batch C3 high drug entrapment efficiency was noted due to high concentration of gluteraldehyde. The drug entrapment efficiency was found to be increased significantly $(p<0.05)$ when concentration of gluteraldehyde was increased. This may be due to increase in cross linking degree of IPNs [27]. Also CMTG concentration had significant effect on entrapment efficiency. This might be due to formation of thick surface which decreases loss of drug due to the high viscosity of CMTG. The results of entrapment efficiency were in good agreement with earlier studies $[6,28]$.

\subsection{Attenuated total reflectance-Fourier transform infrared spectroscopy}

The formation of crosslinked IPNs was confirmed by ATRFTIR analysis (see Figure 2). The CMTG showed peak at $1402 \mathrm{~cm}^{-1}(\mathrm{C}=\mathrm{O})$, which confirms carboxymethylation of tamarind gum [10] and also peak at $1639 \mathrm{~cm}^{-1}$ is due to

Table 1. Formulation of aceclofenac loaded IPNs and entrapment efficiency

\begin{tabular}{cccccc}
\hline Batch & $\begin{array}{c}\text { Chitosan } \\
(\% \mathrm{w} / \mathrm{v})\end{array}$ & $\begin{array}{c}\text { CMTG } \\
(\% \mathrm{w} / \mathrm{v})\end{array}$ & $\begin{array}{c}\text { Aceclofenac } \\
(\% \mathrm{w} / \mathrm{v})\end{array}$ & $\begin{array}{c}\text { Gluteraldehyde } \\
(\mathbf{2 5 \%} \mathbf{w} / \mathbf{v}) \\
(\mathbf{m l})\end{array}$ & $\begin{array}{c}\text { Entrapment efficiency } \\
(\%)\end{array}$ \\
\hline C0 & 0.4 & 0.6 & 00 & 1 & - \\
C1 & 0.4 & 0.6 & 0.8 & 1 & $69.82 \pm 2.56$ \\
C2 & 0.4 & 0.6 & 0.8 & 2 & $78.37 \pm 2.63^{\mathrm{a}}$ \\
C3 & 0.4 & 0.6 & 0.8 & 3 & $78.37 \pm 2.63^{\mathrm{a}}$ \\
C4 & 0.4 & 0.4 & 0.8 & 1 & $61.30 \pm 2.87^{\mathrm{a}}$ \\
C5 & 0.4 & 0.8 & 0.8 & 1 & $73.93 \pm 2.84^{\mathrm{a}}$ \\
\hline
\end{tabular}

CMTG- carboxymethyl tamarind gum; ${ }^{*}$ diluted to $5 \mathrm{ml}$ with distilled water; ${ }^{a}$ statistically significant $(p<0.05)$ than $\mathrm{C} 1$ 


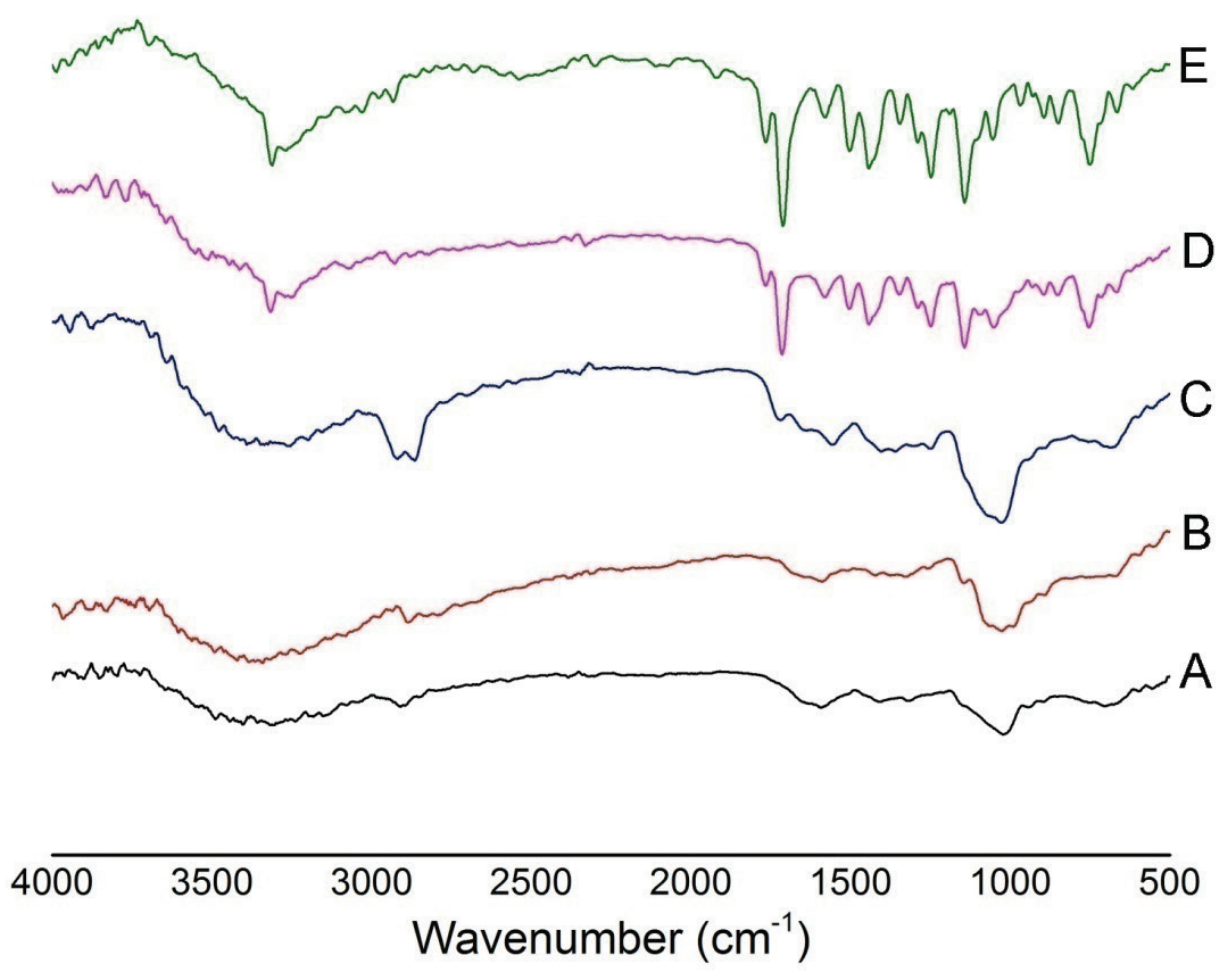

Figure 2. ATR-FTIR of CMTG (A), chitosan (B), blank IPN (C), drug loaded IPN (D), aceclofenac (E)

COO. The broad peak at $3423 \mathrm{~cm}^{-1}$ is of $\mathrm{O}-\mathrm{H}$ stretching and peak at $1010 \mathrm{~cm}^{-1}$ is indicative of C-O-C stretch of glycosidic linkage [18]. The spectra of chitosan showed characteristic peak at $3421 \mathrm{~cm}^{-1}$ due to $\mathrm{N}-\mathrm{H}$ and $-\mathrm{OH}$ stretching. Three peaks appeared at $1650 \mathrm{~cm}^{-1}, 1589 \mathrm{~cm}^{-1}$ and $1375 \mathrm{~cm}^{-1}$ due to amide I, amide II, amide III [29].

The spectra of blank IPNs showed all characteristic peaks of both chitosan and CMTG along with emerging new peaks at $1645 \mathrm{~cm}^{-1}$ and $1028 \mathrm{~cm}^{-1}$ due to $\mathrm{C}-\mathrm{N}$ stretching vibration of imine group of Schiff base formed from $\mathrm{NH}_{2}$ group of chitosan and - $\mathrm{CHO}$ group of gluteraldehyde and an acetal group formed due to $\mathrm{OH}$ group of $\mathrm{CMTG}$ and - $\mathrm{CHO}$ groups of gluteraldehyde respectively. Also, one more peak emerged at $1720 \mathrm{~cm}^{-1}$ of carbonyl group due to formation of linkage between gluteraldehyde and CMTG. This may be attributed to the formation of acetal bridges due to reaction of $-\mathrm{OH}$ group of CMTG with aldehyde group of gluteraldehyde [30]. This confirms the crosslinking of chitosan and CMTG by gluteraldehyde. Further, broadening of $-\mathrm{OH}$ stretching vibration in case of blank IPN suggests the intercalation of polymeric chains due to strong intermolecular interactions including hydrogen bonding of CMTG and chitosan [18]. Similar findings have been reported in case of CMTG-gelatin
IPNs [7]. A peak at $1404 \mathrm{~cm}^{-1}$ in IPNs indicates presence of $\mathrm{C}=\mathrm{O}$ stretch of $-\mathrm{COO}^{-}$ions of $\mathrm{CMTG}^{-1}$ and peak at 1556 $\mathrm{cm}^{-1}$ may be for $\mathrm{N}-\mathrm{H}$ stretch of $\mathrm{NH}_{3}^{+}$of chitosan leading to formation of interpolymer complex between CMTG and chitosan [10]. From the results of ATR-FTIR study it can be concluded that their exists interpolyelectrolyte complex between $-\mathrm{COO}^{-}$group of $\mathrm{CMTG}$ and $-\mathrm{NH}_{3}{ }^{+}$group of chitosan due to electrostatic attraction and formation of crosslinks between CMTG and chitosan by gluteraldehyde.

The ATR-FTIR spectral analysis was also used to confirm chemical stability of aceclofenac in IPNs. The spectra of pure aceclofenac showed principal characteristic peaks at 2934 $\mathrm{cm}^{-1}$ due to $\mathrm{C}-\mathrm{H}$ stretching vibrations and a sharp and intense bands at $1712 \mathrm{~cm}^{-1}$ and $1765 \mathrm{~cm}^{-1}$ due to $\mathrm{C}=\mathrm{O}$ stretching of carboxyl group. A band at $1290 \mathrm{~cm}^{-1}$ is due to $-\mathrm{OH}$ in plain bending vibration and peak at $752 \mathrm{~cm}^{-1}$ is of $\mathrm{C}-\mathrm{Cl}$ stretch. A peak at $3312 \mathrm{~cm}^{-1}$ is due to secondary $\mathrm{N}-\mathrm{H}$ that confirms aceclofenac [28-31].

In case of drug loaded IPNs, all characteristic peaks of aceclofenac were observed with insignificant shifting and reduction in intensity. The peak for $\mathrm{C}=\mathrm{O}$ stretching vibration shifted towards higher frequency indicating hydrogen bonding with IPN network. 


\subsection{Thermal Analysis}

A thermal behavior and physical state of pure aceclofenac in IPN composite was examined through DSC-TGA analysis. Thermal decomposition curve of CMTG shows two main stages of decomposition (Figure 3 TGA). The first stage begins at $35^{\circ} \mathrm{C}$ and ends at $100^{\circ} \mathrm{C}$ with $3.91 \%$ weight loss. This may be due to the removal of free and bound water from the polymer. The second stage of weight loss was observed at $235^{\circ} \mathrm{C}$ to $425^{\circ} \mathrm{C}$ with $54.42 \%$ loss of weight. The total weight loss was found to be $90 \%$ at $485^{\circ} \mathrm{C}$. The weight loss of CMTG in second stage is attributed to the decomposition of the polymer backbone. In case of chitosan first stage started at $35^{\circ} \mathrm{C}$ and ended at $112^{\circ} \mathrm{C}$ with $9.64 \%$ weight loss. The second stage started at $205^{\circ} \mathrm{C}$ and ended at $390^{\circ} \mathrm{C}$ with $52 \%$ weight loss which may be due to the degradation of polymer backbone. The total weight loss at the end of $485^{\circ} \mathrm{C}$ was $81 \%$.

Thermal decomposition curve of IPN shows two main stages of decomposition. The first stage begins at $35^{\circ} \mathrm{C}$ and

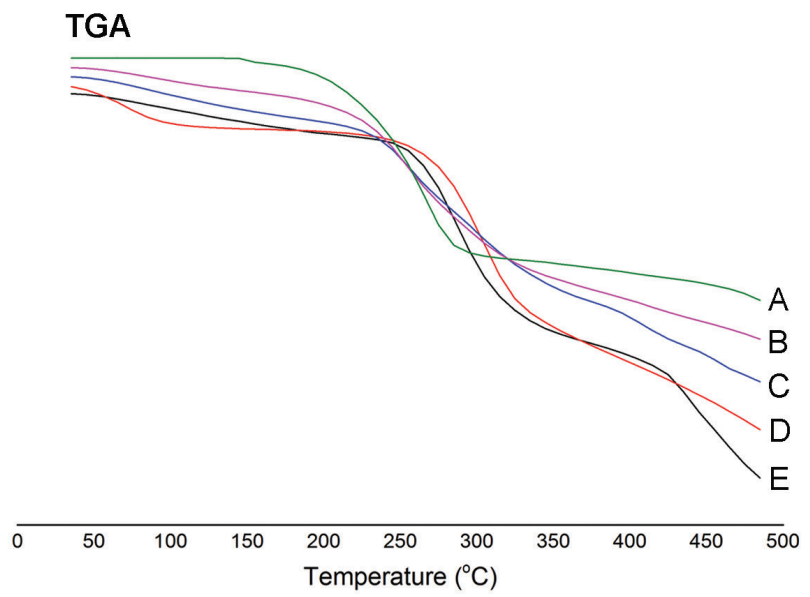

DSC

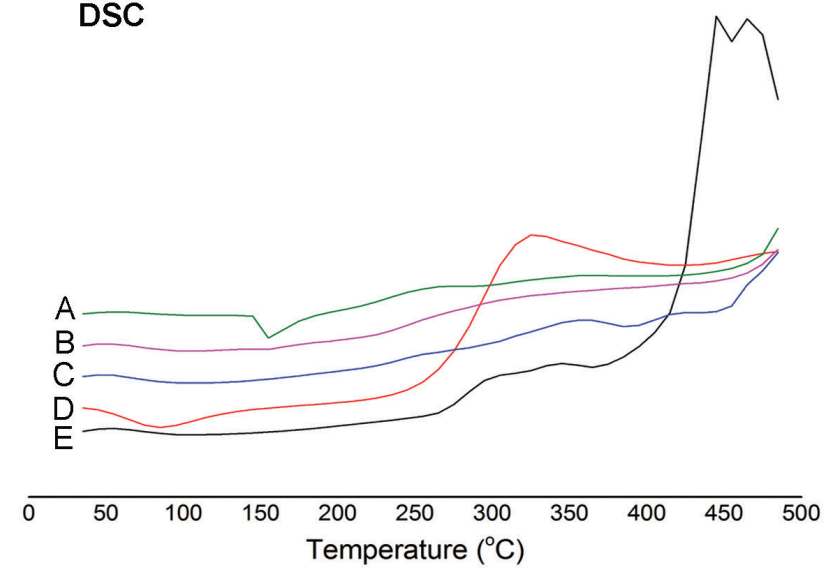

Figure 3. TGA and DSC of aceclofenac (A), drug loaded IPN (B), blank IPN (C), chitosan (D) and CMTG (E) ends at $225^{\circ} \mathrm{C}$ with $13 \%$ loss of weight. İn second stage, $42 \%$ of weight loss was observed between $225^{\circ} \mathrm{C}$ to $395^{\circ} \mathrm{C}$. The total $72 \%$ of weight loss was found at the end of $485^{\circ} \mathrm{C}$. The total weight loss in case of IPN network was found to be reduced significantly than the individual polymer indicating formation of polymeric crosslinked structure with intercalation of polymeric chains of CMTG and chitosan.

Thermal decomposition of aceclofenac shows two stages of decomposition. The first stage starts at $35^{\circ} \mathrm{C}$ and ends at $150^{\circ} \mathrm{C}$ with $1 \%$ weight loss, which may be due to the removal of water. The second stage started at $155^{\circ} \mathrm{C}$ and ended at $335^{\circ} \mathrm{C}$ with $46 \%$ loss in weight. The total weight loss was found to be $56 \%$ at the end of $485^{\circ} \mathrm{C}$. In case of drug loaded IPN, first stage started at $35^{\circ} \mathrm{C}$ and ended at $195^{\circ} \mathrm{C}$ with $9 \%$ weight loss and second stage begins at $195^{\circ} \mathrm{C}$ and ends at $385^{\circ} \mathrm{C}$ with $45 \%$ loss in weight. The total weight loss at the end of $485^{\circ} \mathrm{C}$ was $64 \%$. Thermal stability of drug loaded IPNs was found to be improved than the blank IPNs.

The DSC analysis (Figure 3 DSC) for CMTG, chitosan and blank IPNs was in agreement with TGA curve and suggests the formation of crosslinked IPNs. The DSC of aceclofenac shows a sharp melting endothermic peak at $155.92^{\circ} \mathrm{C}$ [7]. In case of drug loaded IPNs, endotherm of aceclofenac disappeared suggesting the uniform dispersion of aceclofenac at molecular level in the IPNs [6].

\subsection{X-ray powder diffraction}

XRD was performed in order to investigate physical state of drug in IPNs. XRD of aceclofenac, blank IPNs and drug loaded IPNs are given in Figure 4. XRD pattern of pure aceclofenac showed characteristic diffraction peaks at $2 \theta$ of $18.46^{\circ}$, $19.42^{\circ}, 22.26^{\circ}, 25.94^{\circ}, 25.96^{\circ}, 25.98^{\circ}$ and $26^{\circ}$ with different peak intensity indicating crystalline nature of drug. The intensity of characteristic peaks referred for crystalline nature of aceclofenac was found to be decreased in XRD pattern of aceclofenac loaded IPN batch, which could be due to polymeric interaction. The significant reduction in diffraction pattern of aceclofenac loaded IPNs suggest that the crystalline nature of pure aceclofenac is converted to amorphous form [32].

\subsection{Solid sate ${ }^{13} \mathrm{C}$ Nuclear magnetic resonance spectroscopy}

Solid state ${ }^{13} \mathrm{C}$ NMR was performed to investigate compatibility of aceclofenac with IPNs. Aceclofenac shows resonance peaks at $38.05 \mathrm{ppm}$ and $62.57 \mathrm{ppm}$ that are associated with C4 and C2 carbon respectively (see Figure 5). The chemical 


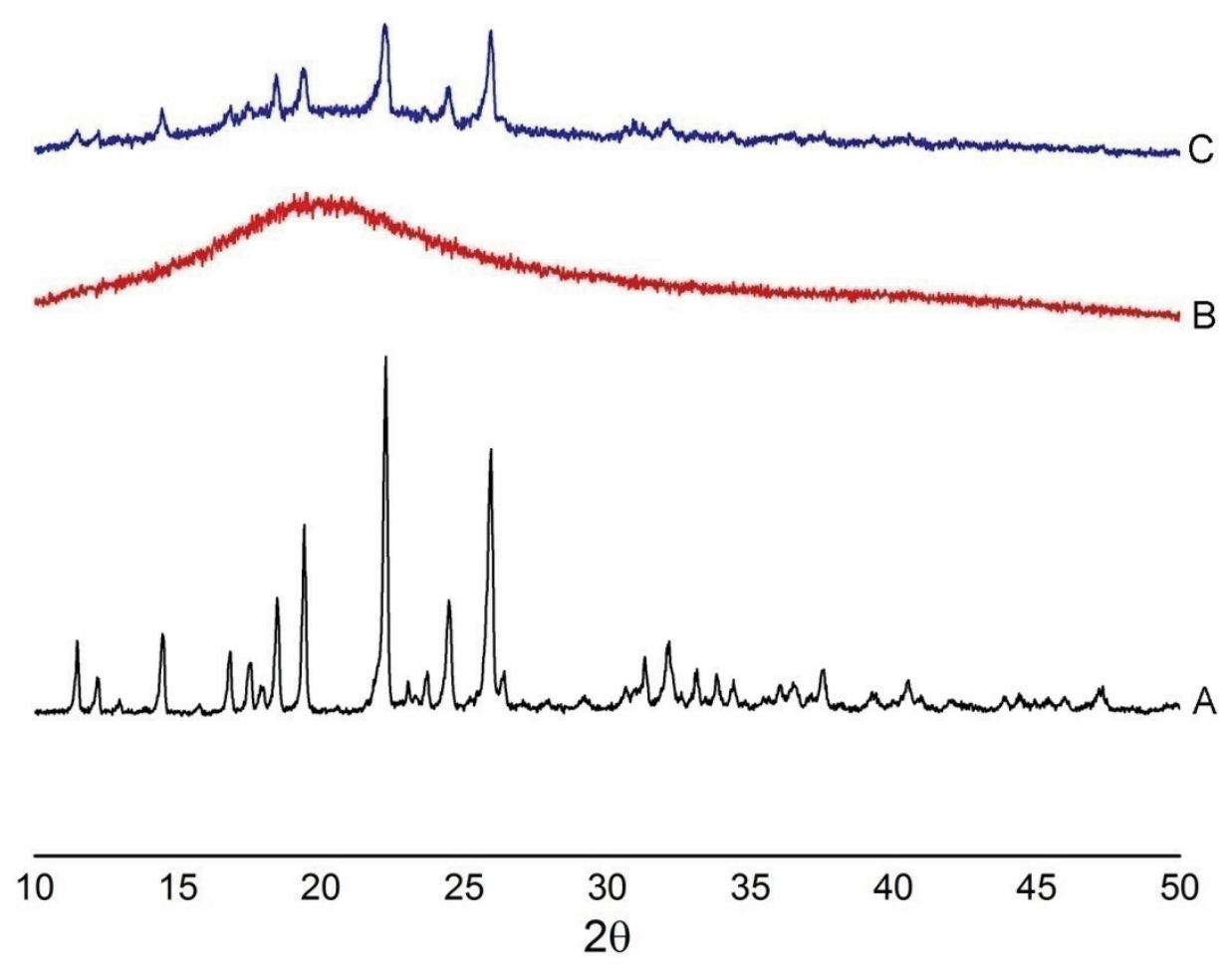

Figure 4. XRD of Aceclofenac (A), blank IPN (B) and aceclofenac loaded IPN (C)

shift from $116.9 \mathrm{ppm}$ to $147.5 \mathrm{ppm}$ is assigned to the benzene carbon atoms (C5 to $\mathrm{C} 10$ and $\mathrm{C} 11$ to $\mathrm{C} 16$ ). The carbonyl carbon of aceclofenac shows chemical shift at $170.7 \mathrm{ppm}$ for C3 and 175.54 for $\mathrm{C} 1$ due to partial ionization of carbonyl group. The benzene ring connected to $-\mathrm{NH}$ by carbon $\mathrm{C} 6$ and $\mathrm{C} 11$ showed chemical shift at $139.3 \mathrm{ppm}$ and $143.5 \mathrm{ppm}$ respectively. The chemical shift at $123.24 \mathrm{ppm}$ is assigned to carbon atom of benzene ring connected to chlorine [31]. In case of aceclofenac loaded IPNs all essential chemical shifts of aceclofenac with slight shifting are seen indicating no any unwanted interaction between drug and IPNs. The peaks of carbonyl carbon for aceclofenac were observed at $170.7 \mathrm{ppm}$ and $175.54 \mathrm{ppm}$ with reduction in intensity, which suggests that there might be formation of hydrogen bonding between aceclofenac and IPNs. Aceclofenac consists of acidic (-COOH) group, while chitosan is having $-\mathrm{NH}_{2}$ group. After ionization of $\mathrm{COOH}$ into $\mathrm{COO}^{-}$and $\mathrm{NH}_{2}$ into $\mathrm{NH}_{3}{ }^{+}$it may be prone to react with each other and able to encapsulate aceclofenac within CMTG - chitosan IPNs. This could be possible reason behind the stabilization of aceclofenac in the IPNs. In case of blank IPNs broad resonance peak was observed at $179.6 \mathrm{ppm}$, which may be due to free carbonyl group of CMTG and the carbonyl group formed due to crosslinked CMTG [33].

\subsection{Equilibrium swelling}

The site specific drug delivery is reliant on the $\mathrm{pH}$ of medium. Factors which contribute in swelling of ionic polymers like CMTG and chitosan may include polymer charge, concentration and $\mathrm{pKa}$ of ionizable group, degree of ionization, crosslinking density, hydrophilicity and hydrophobicity as well as $\mathrm{pH}$ of swelling medium. The equilibrium swelling of aceclofenac loaded IPNs was determined in $0.1 \mathrm{~N} \mathrm{HCl}$ and phosphate buffer $\mathrm{pH} 6.8$ (see Figure 6). The variation of equilibrium swelling may be due to the fact that IPNs in contact with swelling medium, prevents expansion of its three dimensional hydrophilic network. The expansion is prevented by the extent of crosslinking and provides an elastic response which affects the swelling of IPNs [34].

IPNs showed significantly low $(P<0.05)$ swelling in $0.1 \mathrm{~N} \mathrm{HCl}$ than the phosphate buffer $\mathrm{pH}$ 6.8. CMTG is anionic polymer which is in unionized state in the acidic environment. The $\mathrm{pH}$ of $0.1 \mathrm{~N} \mathrm{HCl}$ solution is less than the $\mathrm{pKa}$ of the carboxyl group [4-5] present in CMTG, leading to decreased electrostatic repulsion due to protonation of carboxylic groups $(\mathrm{COOH})$. This retards swelling owing to reduction in water uptake capacity of IPNs [35]. The chitosan is a cationic hydrophobic 


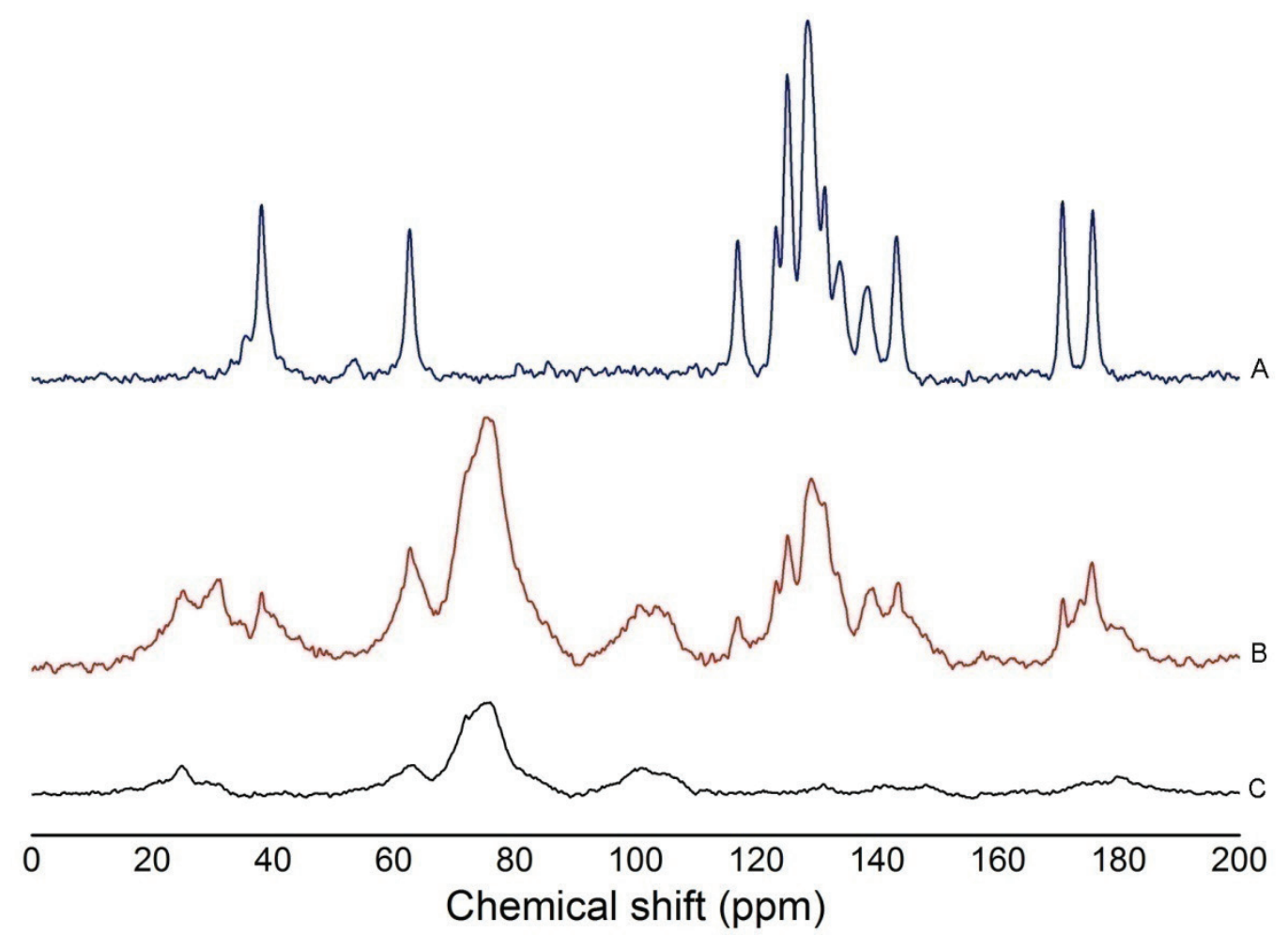

Figure 5. Solid sate ${ }^{13} \mathrm{C}$ NMR of Aceclofenac (A), drug loaded IPN (B) and blank IPN (C)

polymer. The most of the amino groups of chitosan are crosslinked by the gluteraldehyde and remaining may be associated with the CMTG. This could be due to formation of polyelectrolyte complex between the CMTG ( $\left.\mathrm{COO}^{-}\right)$and chitosan $\left(\mathrm{NH}_{3}^{+}\right)$due to $\mathrm{NH}_{3}{ }^{+} \mathrm{COO}$ linkage. These crosslinks and polymeric complex were stable in the acidic environment $[7,10]$. These factors may be responsible for the decrease in the swelling of IPNs at acidic $\mathrm{pH}$. When concentration of CMTG was increased in the IPNs, the equilibrium swelling was found to be increased. This might be due to hydrophilic nature of the CMTG [16]. The results were in agreement with the earlier reports by Kaur et al [10].

In case of $\mathrm{C} 5$ batch, high values of swelling in phosphate buffer $\mathrm{pH} 6.8$ may be attributed to electrostatic repulsion of ionized carbonyl ( $\mathrm{COO}^{-}$) groups due to deprotonation of CMTG which increases the polymer mobility and enhances mesh size of network there by increasing the equilibrium swelling. Also, crosslinks formed by gluteraldehyde and the $\mathrm{NH}_{3}{ }^{+} \mathrm{COO}$ links may be unstable at $\mathrm{pH} 6.8$ and contributes to enhancement in the equilibrium swelling of IPN $[7,10]$. When the concentration of gluteraldehyde was increased in IPNs (C1-C3) equilibrium swelling was found to be decreased. The batch C3 showed very low swelling because of high crosslinking density of IPNs due to reduction in mobility, relaxation and expansion of the polymer chains.

The results of swelling study in $0.1 \mathrm{~N} \mathrm{HCl}$ and phosphate buffer clearly indicates the $\mathrm{pH}$ dependent swelling of CMTGchitosan IPNs. It suggests the suitability of IPNs for oral site specific delivery of drug in order to avoid exposure of drug to erratic gastric environment and drug release in the intestine.

\subsection{In vitro drug release}

The in vitro drug release of formulated IPNs was determined by using dialysis bag diffusion technique. The in vitro drug release was carried out in $0.1 \mathrm{~N} \mathrm{HCl}$ for $2 \mathrm{~h}$ followed by phosphate buffer $\mathrm{pH} 6.8$ up to 12h [7]. The IPNs showed less than $5 \%$ of drug release in $0.1 \mathrm{~N} \mathrm{HCl}$ at the end of $2 \mathrm{~h}$ followed by controlled release in phosphate buffer $\mathrm{pH} 6.8$ over period of $12 \mathrm{~h}$ (see Figure 7). The results of in vitro release indicated $\mathrm{pH}$ dependent sustained release of aceclofenac from IPNs.

The results also indicated that, when the concentration of crosslinker (C1-C3) is increased from 1 to $3 \mathrm{ml}$ the drug release was found to be decreased in phosphate buffer, $\mathrm{pH}$ 6.8. This may be due to increased degree of crosslinking 


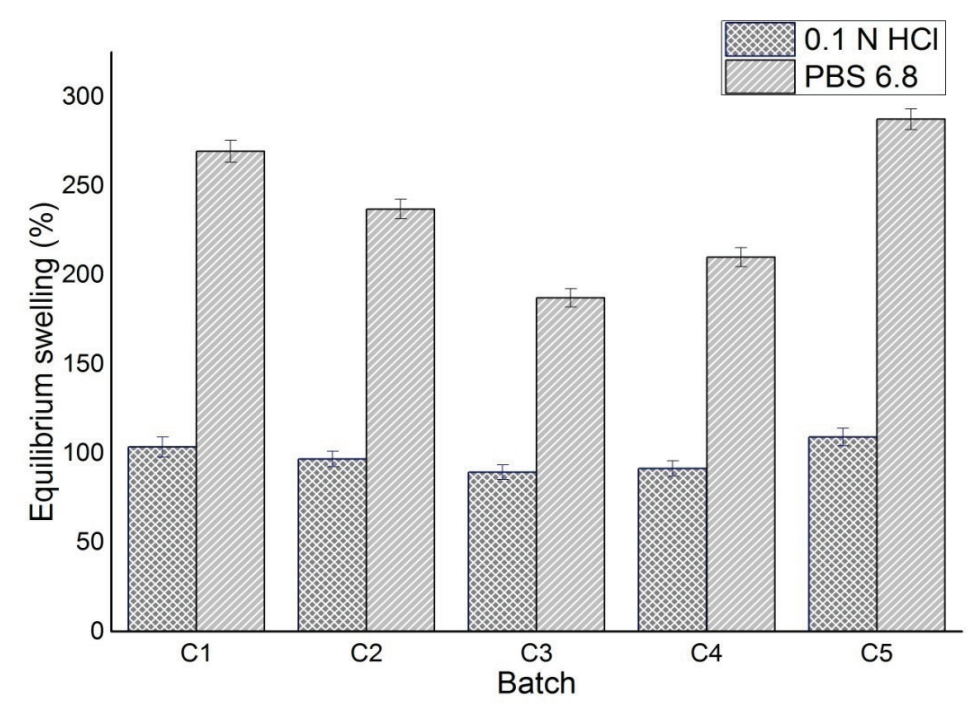

Figure 6. Equilibrium swelling (\%) of IPNs in $0.1 \mathrm{~N} \mathrm{HCl}$ and phosphate buffer $\mathrm{pH} 6.8$

within polymeric network resulting in retardation of drug release from IPNs [6]. In case of batch C5, high concentration of CMTG in IPNs also retarded drug release. This may be due to high swelling of CMTG in phosphate buffer which increased the path length to diffuse out the drug into bulk of solution. Drug release from commercial tablet was found to be faster than IPNs and 100\% of drug was released at the end of $8 \mathrm{~h}$ while IPNs extended release upto $12 \mathrm{~h}$. The fast release of drug from the commercial tablet in PBS pH 6.8 may be attributed to the dispersion of drug into the polymer matrix. In case of IPNs, drug gets entrapped in the network matrix at molecular level from which it gets released at slower rate than the commercial formulation.
The release data was fitted into the zero order, Higuchi and Korsmeyer-Peppas equation to investigate release mechanism from IPNs [36]. In vitro release parameters like mean dissolution time (MDT), dissolution efficiency (DE) and release kinetics is given in Table 2. The value of MDT was found to be in the range of 4.08 to $4.76 \mathrm{~h}$ where as dissolution efficiency was found to be in the range of 40.46 to $59.02 \%$. All IPN batches followed the zero order kinetics while commercial formulation followed Higuchi kinetics model. The ' $n$ ' is the diffusional coefficient obtained from Korsmeyer-Peppas equation which depends upon the interaction in between drug and the components of IPN matrix. The result of diffusion coefficient (n) and release

Table 2. In vitro release parameters of aceclofenac from IPNs

\begin{tabular}{|c|c|c|c|c|c|c|c|}
\hline \multirow[t]{2}{*}{ Batch } & \multirow{2}{*}{$\begin{array}{l}\text { Drug release at } 12 \mathrm{~h} \\
(\%)\end{array}$} & \multirow{2}{*}{$\begin{array}{l}\mathrm{DE} \\
(\%)\end{array}$} & \multirow{2}{*}{$\begin{array}{c}\text { MDT } \\
\text { (h) }\end{array}$} & \multirow{2}{*}{$\begin{array}{c}\text { Zero order } \\
\mathrm{r}\end{array}$} & \multirow{2}{*}{$\begin{array}{c}\text { Higuchi } \\
\mathrm{r}\end{array}$} & \multicolumn{2}{|c|}{ Korsmeyer-Peppas } \\
\hline & & & & & & $\mathrm{r}$ & $\mathrm{n}$ \\
\hline $\mathrm{C} 1$ & 93.64 & 52.98 & 4.34 & 0.998 & 0.989 & 0.995 & 0.75 \\
\hline $\mathrm{C} 2$ & 84.47 & 45.95 & 4.55 & 0.999 & 0.987 & 0.997 & 0.80 \\
\hline $\mathrm{C} 3$ & 70.11 & 36.71 & 4.76 & 0.999 & 0.981 & 0.995 & 0.86 \\
\hline $\mathrm{C} 4$ & 99.71 & 59.02 & 4.08 & 0.997 & 0.995 & 0.997 & 0.68 \\
\hline C5 & 74.13 & 40.46 & 4.54 & 0.999 & 0.988 & 0.998 & 0.79 \\
\hline $\mathrm{CF}$ & 99.79 & 60.93 & 2.33 & 0.974 & 0.991 & 0.991 & 0.66 \\
\hline
\end{tabular}

DE- dissolution efficiency; MDT-mean dissolution time; CF- commercial formulation r- correlation coefficient; n-release exponent 


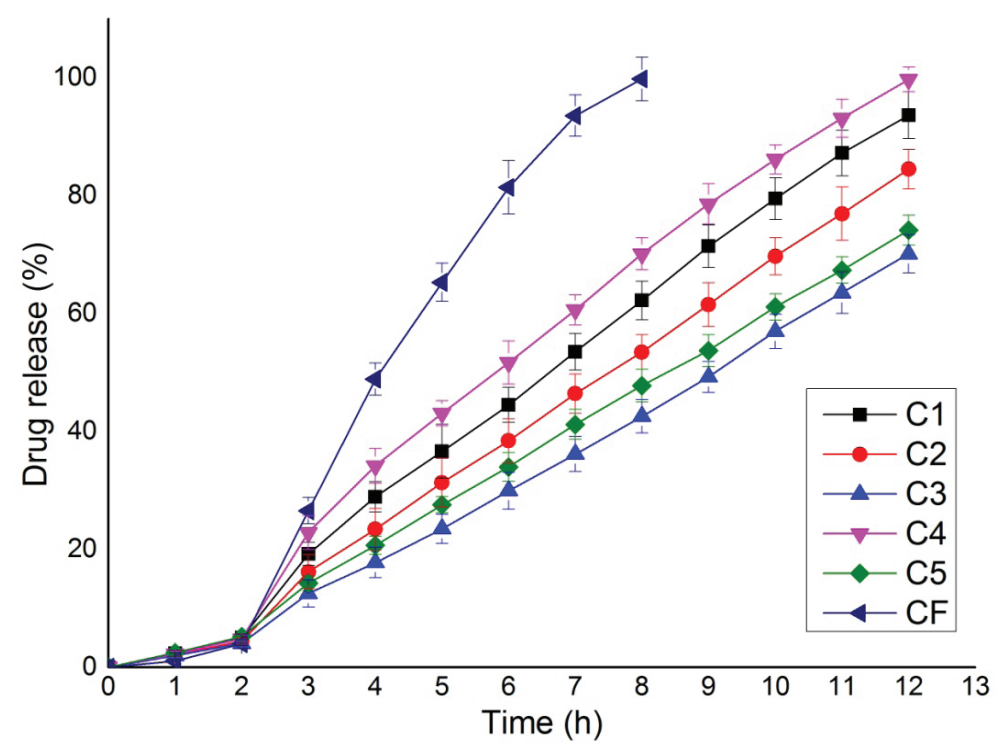

Figure 7. Drug release of aceclofenac from IPNs and commercial formulation (CF)

mechanism is given in Table 2. All batches of IPNs showed Non-Fickian release behavior. The value of diffusion coefficient was found to be greater than 0.5 indicating high interaction between drug and IPNs and drug was released by diffusion coupled with erosion mechanism. The value of ' $n$ ' was found to be increased when concentration of crosslinker and CMTG was increased.

\section{Conclusion}

The IPNs of CMTG and chitosan were successfully developed. CMTG and chitosan has ability to form the polyelecrolyte complex due to electrostatic attraction between $-\mathrm{COO}^{-}$ group of CMTG and $\mathrm{NH}_{3}{ }^{+}$of chitosan. ATR-FTIR and thermal analysis confirmed the formation of gluteraldehyde crosslinked IPNs. DSC and XRD study revealed the conversion of crystalline aceclofenac to the amorphous form and formation of molecular dispersion of aceclofenac into IPNs. The aceclofenac was incorporated into the IPNs with high entrapment efficiency. The equilibrium swelling study showed the $\mathrm{pH}$ dependent swelling of IPNs. Aceclofenac showed the site specific sustained drug release in phosphate buffer pH 6.8 with non-Fickian drug release. From results, it can be concluded that the drug loaded crosslinked IPNs of CMTG and chitosan can be used for the oral site specific sustained delivery of drugs. Further, in vivo study can be addressed to confirm the suitability of IPNs for oral sustained delivery of drugs.

\section{Materials and Methods}

Carboxymethyl tamarind gum (Degree of substitution 0.16) was kindly gifted by Tamarind Magic, Hyderabad, India. Chitosan (degree of acetylation- 83\%) was obtained from SD Fine Lab, Mumbai, India. Aceclofenac was obtained as a gift sample from Micro Labs., Bangalore, India. The gluteraldehyde $(25 \% \mathrm{w} / \mathrm{v})$ was supplied by Loba Chemie, Mumbai, Maharashtra (India). All other chemicals were of analytical grade and used as received. Commercial tablet of aceclofenac (Dolokind SR) was purchased from local market.

\subsection{Preparation of interpenetrating networks (IPNs)}

Aceclofenac IPNs were prepared by slight modification in earlier reported method $[6,8]$. In brief, a mixture of carboxymethyl tamarind gum $(0.6 \% \mathrm{w} / \mathrm{v})$ and aceclofenac $(0.8 \% \mathrm{w} / \mathrm{vs})$ was magnetically stirred (Remi, India) at 500rpm for 30 minutes in distilled water. This mixture was added to 
a chitosan solution $(0.4 \% \mathrm{w} / \mathrm{v})$ in $1 \%$ aqueous acetic acid with $0.5 \mathrm{ml}$ of Tween 80 and stirred to homogenize for one hour on mechanical stirrer (RQG126D, Remi, India). A measured quantity of aqueous gluteraldehyde $(25 \% \mathrm{w} / \mathrm{v}$ diluted up to $5 \mathrm{ml}$ ) was added at two minute time interval for $10 \mathrm{~min}$ and stirred for further $10 \mathrm{~min}$. The mixture was kept for $1 \mathrm{~h}$ to remove entrapped air bubbles and then filtered. The filtrate was washed with water to remove unreacted content. Washed IPNs were transferred to petriplate and subjected to drying for complete removal of water at $40^{\circ} \mathrm{C}$ in hot air oven (BioTechnic, Mumbai, India). The detailed composition of IPNs batches is given in Table 1. Blank batch of IPNs was also prepared.

\subsection{Attenuated total reflectance-Fourier transform infrared spectroscopy}

The infrared spectra of CMTG, chitosan, physical mixtures, blank IPNs and aceclofenac loaded IPNs were obtained using ATR-FTIR spectrophotometer (Shimadzu, Miracle 10, IR Affinity, Japan). The samples to be analyzed were placed onto the ATR and spectra were recorded in the range of 600-4000 $\mathrm{cm}^{-1}$ at an average of $25 \mathrm{scans}$ and resolution of $4 \mathrm{~cm}^{-1}$.

\subsection{Thermal analysis}

Thermogravimetric analysis (TGA) and differential scanning calorimetry (DSC) of CMTG, chitosan, blank IPNs, drug loaded IPNs and aceclofenac was performed using MettlerToledo TGA/DSC1 thermogravimetric analyzer (MettlerToledo, Switzerland). Samples were heated from $30^{\circ} \mathrm{C}-500^{\circ} \mathrm{C}$ at the rate of $10^{\circ} \mathrm{C} / \mathrm{min}$, under nitrogen atmosphere (flow rate: $10 \mathrm{ml} / \mathrm{min}$ ).

\subsection{X-ray powder diffraction}

X-ray diffraction (XRD) patterns of aceclofenac, blank IPNs and drug loaded IPNs were recorded using X-ray diffractometer (PW1729, Philips, The Netherlands) with a copper target, operated at voltage of $30 \mathrm{kV}, 30 \mathrm{~mA}$ current, at $2^{\circ} \mathrm{C} / \mathrm{min}$ scanning speed and scanning angle ranging from 0 to $50^{\circ}(2 \theta)$.

\subsection{Solid sate ${ }^{13} \mathrm{C}$ Nuclear magnetic resonance spectroscopy}

Solid state ${ }^{13} \mathrm{C}$ cross-polarization-magic angle spinning (CP-MAS) NMR spectra of aceclofenac, blank IPNs and drug loaded IPNs was measured using JEOL-ECX400 spectrometer operating at $400 \mathrm{MHz}$ (contact time of $3.5 \mathrm{~ms}$, relaxation delay of $5 \mathrm{~s}$, sweep width of $35 \mathrm{kHz}$ and spinning speed of $10 \mathrm{KHz}$ ). The chemical shifts were calibrated with the external hexamethylbenzene standard methyl resonance at $17.3 \mathrm{ppm}$.

\subsection{Drug entrapment efficiency}

Accurately weighed quantity (100mg) of aceclofenac loaded IPNs were transferred to $100 \mathrm{ml}$ volumetric flask and volume was adjusted to $100 \mathrm{ml}$ with phosphate buffer, $\mathrm{pH}$ 6.8. Resultant mixture was stirred for $24 \mathrm{~h}$ using magnetic stirrer (Remi, India) at 100rpm and sonicated for $30 \mathrm{~min}$. The solution was filtered through $0.44 \mu$ membrane filter paper and drug content in filtrate was determined using UV-Vis spectrophotometer (UV 1800, Shimadzu, Japan) at $273 \mathrm{~nm}$. The drug entrapment efficiency of IPNs was calculated using following formula:

Drug entrapment efficiency $(\%)=\frac{\text { Drug content in IPNs }}{\text { Theoretical drug content in IPNs }} \times 100$

\subsection{Equilibrium swelling}

Known amount (100mg) of IPNs were transferred to $100 \mathrm{ml}$ of $0.1 \mathrm{~N} \mathrm{HCl}$ and phosphate buffer $\mathrm{pH} 6.8$ separately and allowed to swell for $24 \mathrm{~h}$ at room temperature. IPNs were separated after $24 \mathrm{~h}$ and excess water was blotted with filter paper and reweighed again [7]. Finally equilibrium swelling index of formulated batches was calculated by using formula:

Equilibrium swelling $(\%)=\frac{\text { Swollen weight } 6 \text { IPNs }- \text { Dry weight } 6 \text { IPNs }}{\text { Dry weight } 6 \text { IPNs }} \times 100$

\subsection{In vitro drug release study}

In vitro drug release from formulated IPNs was determined by using dialysis bag diffusion technique. Accurately weighed IPNs equivalent to $\sim 200 \mathrm{mg}$ of aceclofenac were placed in dialysis bag which was tied and immersed in dissolution vessel containing phosphate buffer $\mathrm{pH}$ 6.8, using Type II USP Apparatus (Electrolab, Mumbai, India). The system was maintained at $37^{\circ} \mathrm{C}$ with stirring speed of $50 \mathrm{rpm}$. The aliquots ( $2 \mathrm{ml}$ diluted up to $10 \mathrm{ml}$ ) were collected from dissolution vessel at regular time interval and replenished with the fresh dissolution media to maintain the sink condition. Collected samples were filtered, diluted and absorbance was measured at $273 \mathrm{~nm}$ by using UV spectrophotometer (UV 1800, Shimadzu, Japan) [6]. 


\subsection{Statistical analysis}

Data was expressed in mean with standard deviation. Statistical data analysis was performed using one-way ANOVA. The $P$ value less than 0.05 were considered statistically significant.

\section{Acknowledgements}

Authors are thankful to the President of YSPM's Yashoda Technical Campus, Satara, for providing necessary facilities for carrying out the research work. Shivaji University, Kolhapur and NMR facility centre of Indian Institute of Science, Bangalore is acknowledged for assistance with analytical work. Also, authors are thankful to Micro Labs., Bangalore, India and Tamarind Magic, Hyderabad for providing gift sample of aceclofenac and carboxymethyl tamarind gum respectively.

\section{Conflict of interest statement}

All authors approve the final manuscript and declare that there are no conflicts of interests.

\section{References}

1. Jana S, Sen KK, Basu SK. In vitro aceclofenac release from IPN matrix tablets composed of chitosan-tamarind seed polysaccharide. Int J Biol Macromol 2014;65:241-5.

2. Roy H, Brahma CK, Nandi S, Parida KR. Formulation and design of sustained release matrix tablets of metformin hydrochloride: Influence of hypromellose and polyacrylate polymers. Int J Appl basic Med Res 2013;3:55-63.

3. Salunke PA, Wagh RS, Patil SS, Barhate SD. An Overview: Site Specific Drug Delivery System. Indo Am J Pharm Sci 2016;3:57-72.

4. Changez M, Burugapalli K, Koul V, Choudhary V. The effect of composition of poly(acrylic acid)-gelatin hydrogel on gentamicin sulphate release: In vitro. Biomaterials 2003;24:527-36.

5. Boppana R, Kulkarni R V., Mutalik SS, Setty CM, Sa B. Interpenetrating network hydrogel beads of carboxymethylcellulose and egg albumin for controlled release of lipid lowering drug. J Microencapsul 2010;27:337-44.

6. Jana S, Saha A, Nayak AK, Sen KK, Basu SK. Aceclofenacloaded chitosan-tamarind seed polysaccharide interpenetrating polymeric network microparticles. Colloids Surfaces B Biointerfaces 2013;105:303-9.

7. Jana S, Banerjee A, Sen KK, Maiti S. Gelatin-carboxymethyl tamarind gum biocomposites: In vitro characterization \& anti-inflammatory pharmacodynamics. Mater Sci Eng C 2016;69:478-85.
8. Kulkarni RV, Mutalik S, Mangond BS, Nayak UY. Novel interpenetrated polymer network microbeads of natural polysaccharides for modified release of water soluble drug: Invitro and in-vivo evaluation. J Pharm Pharmacol 2012;64:53040.

9. Bhattarai N, Gunn J, Zhang M. Chitosan-based hydrogels for controlled, localized drug delivery. Adv Drug Deliv Rev 2010;62:83-99.

10. Kaur G, Jain S, Tiwary AK. Chitosan-carboxymethyl tamarind kernel powder interpolymer complexation: Investigations for colon drug delivery. Sci Pharm 2010;78:57-78.

11. Assa F, Jafarizadeh-Malmiri H, Ajamein H, Vaghari $H$, Anarjan $\mathrm{N}$, Ahmadi O, Berenjian A. Chitosan magnetic nanoparticles for drug delivery systems. Crit Rev Biotechnol 2016;37:1-18.

12. Nayak AK, Pal D, Santra K. Development of calcium pectinatetamarind seed polysaccharide mucoadhesive beads containing metformin HCl. Carbohydr Polym 2014;101:220-30.

13. Mali KK, Dhawale SC, Dias RJ. Microemulsion based bioadhesive gel of itraconazole using tamarind gum: In-vitro and ex-vivo evaluation. Marmara Pharm J 2017;21: 688-700.

14. Kaur H, Ahuja M, Kumar S, Dilbaghi N. Carboxymethyl tamarind kernel polysaccharide nanoparticles for ophthalmic drug delivery. Int J Biol Macromol 2012;50:833-9.

15. Goyal P, Kumar V, Sharma P. Carboxymethylation of Tamarind kernel powder. Carbohydr Polym 2007;69:251-5.

16. Pal S, Sen G, Mishra S, Dey RK, Jha U. Carboxymethyl tamarind: Synthesis, characterization and its application as novel drug-delivery agent. J Appl Polym Sci 2008;110:392400.

17. Mali KK, Dhawale SC. Design and optimization of modified tamarind gum-based floating-bioadhesive tablets of verapamil hydrochloride. Asian J Pharm 2016;10:2-8.

18. Jana S, Sharma R, Maiti S, Sen KK. Interpenetrating hydrogels of O-carboxymethyl Tamarind gum and alginate for monitoring delivery of acyclovir. Int J Biol Macromol 2016;92:1034-9.

19. Ahuja M. Metronidazole loaded carboxymethyl tamarind kernel polysaccharide-polyvinyl alcohol cryogels: Preparation and characterization. Int J Biol Macromol 2015;72:931-8.

20. Mali K, Dhawale S, Dias R, Havaldar V, Ghorpade V, Salunkhe $\mathrm{N}$. Nasal mucoadhesive in situ gel of granisetron hydrochloride using natural polymers. J Appl Pharm Sci 2015;5:84-93.

21. Sanyasi S, Kumar A, Goswami C, Bandyopadhyay A, Goswami L. A carboxy methyl tamarind polysaccharide matrix for adhesion and growth of osteoclast-precursor cells. Carbohydr Polym 2014;101:1033-42.

22. Shaw GS, Uvanesh K, Gautham SN, Singh V, Pramanik K, Banerjee I, Kumar N, Pal K. Development and characterization of gelatin-tamarind gum/carboxymethyl tamarind gum based phase-separated hydrogels: A comparative study. Des Monomers Polym 2015;18:434-50.

23. Shaw GS, Biswal D, B A, Banerjee I, Pramanik K, Anis A, Pal K. Preparation, characterization and assessment of the novel gelatin-tamarind gum/carboxymethyl tamarind gum-based phase-separated films for skin tissue engineering applications. Polym Plast Technol Eng 2017;56:141-52.

24. Sanyasi S, Majhi RK, Kumar S, Mishra M, Ghosh A, Suar M, Satyam PV, Mohapatra H, Goswami C, Goswami L. 
Polysaccharide-capped silver Nanoparticles inhibit biofilm formation and eliminate multi-drug-resistant bacteria by disrupting bacterial cytoskeleton with reduced cytotoxicity towards mammalian cells. Sci Rep 2016;6:24929.

25. Trivedi JH. Synthesis, characterization, and swelling behavior of superabsorbent hydrogel from sodium salt of partially carboxymethylated tamarind kernel powder-g-PAN. J Appl Polym Sci 2013;129:1992-2003.

26. Jana S, Das A, Nayak AK, Sen KK, Basu SK. Aceclofenac-loaded unsaturated esterified alginate/gellan gum microspheres: In vitro and in vivo assessment. Int J Biol Macromol 2013;57:12937.

27. Kulkarni RV, Mangond BS, Mutalik S, Sa B. Interpenetrating polymer network microcapsules of gellan gum and egg albumin entrapped with diltiazem-resin complex for controlled release application. Carbohydr Polym 2011;83:1001-7.

28. Jana S, Gandhi A, Sheet S, Sen KK. Metal ion-induced alginatelocust bean gum IPN microspheres for sustained oral delivery of aceclofenac. Int J Biol Macromol 2015;72:47-53.

29. Balaji R, Raghunathan S, Revathy R. Levofloxacin: formulation and in-vitro evaluation of alginate and chitosan nanospheres. Egypt Pharm J 2015;14:30.

30. Distantina S, Rochmadi, Fahrurrozi M, Wiratni. Preparation of hydrogel based on glutaraldehyde-crosslinked carrageenan. 3rd International Conference on Chemistry and Chemical Engineering 2012;38:150-4.

31. Suresh S, Gunasekaran S, Srinivasan S. Studies of the molecular geometry, vibrational spectra, frontier molecular orbital, nonlinear optical and thermodynamics properties of aceclofenac by quantum chemical calculations. Spectrochim Acta A Mol Biomol Spectrosc 2014;125:239-51.

32. Deshmukh RK, Naik JB. Aceclofenac microspheres: Quality by design approach. Mater Sci Eng C. 2014;36:320-8.

33. Ghorpade VS, Yadav AV, Dias RJ. Citric acid crosslinked $\beta$-cyclodextrin/carboxymethylcellulose hydrogel films for controlled delivery of poorly soluble drugs. Carbohydr Polym 2017;164:339-48.

34. Sannino A, Maffezzoli A, Nicolais L. Introduction of molecular spacers between the crosslinks of a cellulose-based superabsorbent hydrogel: Effects on the equilibrium sorption properties. J Appl Polym Sci 2003;90:168-74.

35. Seki Y, Altinisik A, Demircioğlu B, Tetik C. Carboxymethylcellulose (CMC)-hydroxyethylcellulose (HEC) based hydrogels: Synthesis and characterization. Cellulose 2014;21:1689-98.

36. Costa P, Sousa Lobo JM. Modeling and comparison of dissolution profiles. Eur J Pharm Sci 2001;13:123-33. 